
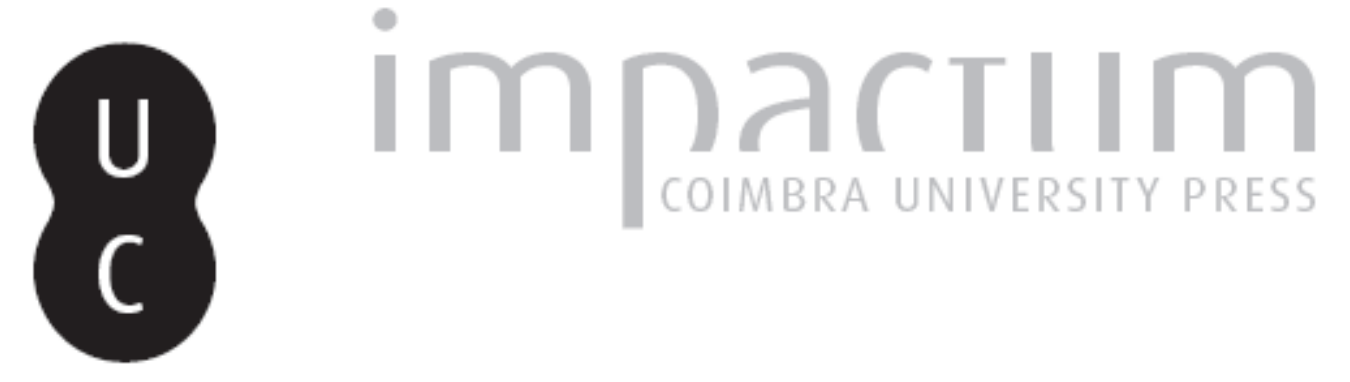

\title{
A sombra de Carlos Alberto
}

\section{Autor(es): $\quad$ Rodrigues, Ernesto}

Publicado por: Imprensa da Universidade de Coimbra

URL persistente:

URI:http://hdl.handle.net/10316.2/42547

DOI:

DOI:https://doi.org/10.14195/0870-8584_6_5

Accessed : $\quad$ 26-Apr-2023 16:09:35

A navegação consulta e descarregamento dos títulos inseridos nas Bibliotecas Digitais UC Digitalis, UC Pombalina e UC Impactum, pressupõem a aceitação plena e sem reservas dos Termos e Condições de Uso destas Bibliotecas Digitais, disponíveis em https://digitalis.uc.pt/pt-pt/termos.

Conforme exposto nos referidos Termos e Condições de Uso, o descarregamento de títulos de acesso restrito requer uma licença válida de autorização devendo o utilizador aceder ao(s) documento(s) a partir de um endereço de IP da instituição detentora da supramencionada licença.

Ao utilizador é apenas permitido o descarregamento para uso pessoal, pelo que o emprego do(s) título(s) descarregado(s) para outro fim, designadamente comercial, carece de autorização do respetivo autor ou editor da obra.

Na medida em que todas as obras da UC Digitalis se encontram protegidas pelo Código do Direito de Autor e Direitos Conexos e demais legislação aplicável, toda a cópia, parcial ou total, deste documento, nos casos em que é legalmente admitida, deverá conter ou fazer-se acompanhar por este aviso.

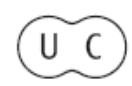




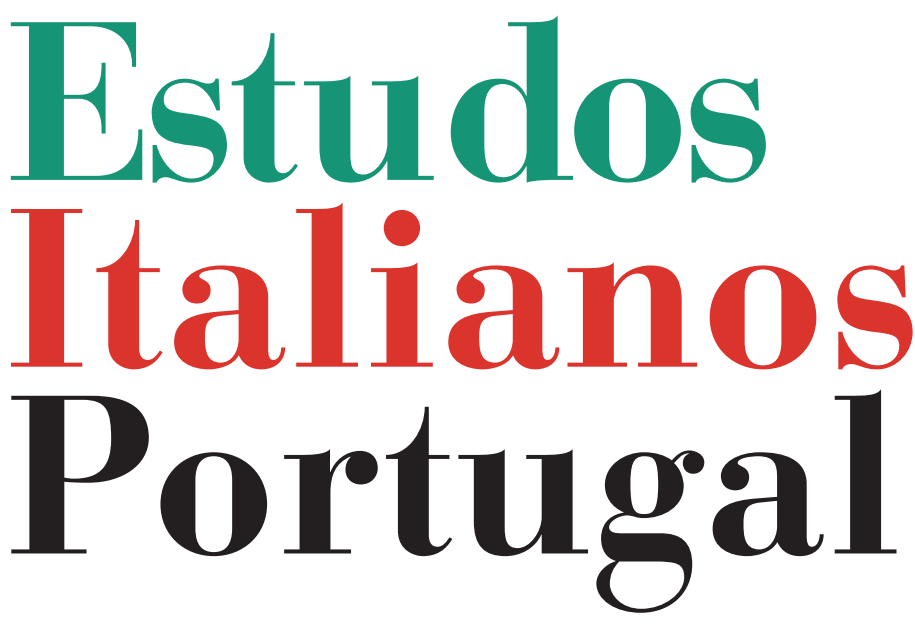

Instituto

Italiano

de Cultura

de Lisboa

Nova Série

$\mathrm{N}^{\circ} 6$ 


\section{A SOMBRA DE CARLOS ALBERTO}

ERNESTO RODRIGUES*

Vai Júlio César Machado Do Chiado a Veneza (1867), retorna e ninguém pergunta "pello effeito que produzira no meu espírito esse paiz encantador a que chamam merecidamente o jardim da Europa, [...]" (p. 20). A guerra "infallivel" de Victor Manuel é a única preocupação: "E este fallava-me no quadrilatero, aquelle desejava informar-se do feitio dos austríacos, o outro queria saber se a miseria levava já Veneza a comer a carne escura dos seus pombos, o outro fallava-me de Garibaldi, e o outro queria noticias do Persano" (p. 21) - mas nenhum queria nada com Miguel Ângelo. Hoje, quem saberá do 'quadrilátero' - os fortes de Peschiera, Mântua, Legnano e Verona - e do conde Carlo Pellian di Persano, almirante e senador, que, derrotado em Lissa (20-7-1866), voltou para casa gritando vitória naval sobre os austríacos, antes de ser julgado (Janeiro de 1867), destituído e humilhado? Hoje, ao invés, quem saberá do aportuguesado nome de Carlos Alberto (influindo, decerto, na fortuna deste duplo nome próprio; o mesmo se dirá de Vítor / Victor Manuel), além de toponimizar praça portuense? Se Garibaldi se estende mais proveitosamente, entrando pelo movimento republicano português - de Francisco Gomes de Amorim, n'O Patriota (1848, com o poema Garibaldi), à Galeria Re-

\footnotetext{
* Ensaísta e tradutor. Professor da Faculdade de Letras da Universidade de Lisboa.
} 
publicana $\left(1882\right.$, n. $\left.{ }^{\circ} 15,19\right)$-, não pouco avança $A$ sombra de Carlos Alberto, parafraseando poema de Ramos Coelho no consórcio de D. Luís e D. Maria Pia (AA. VV., Coroa Poética [...], 1862; com repetidas edições, também da versão L'ombra di Carlo Alberto in Campidoglio, na lírica de autor bem relacionado com italianos). Vamos pontuá-la, servindo-nos de bibliografia não explorada, no efeito que o infeliz rei produziu e nas manifestações de júbilo e dor que a sua curta estada no Porto suscitou.

O primeiro passo é retrospectivar "Documentos para a história das relaçóes intelectuais luso-italianas / Bibliografia Portoghese del Risorgimento Italiano", que Giacinto Manuppella reuniu no Boletim Internacional de Bibliografia Luso-Brasileira ${ }^{1}$. Após breve preâmbulo em que se propóe a data terminal de 1870 (mas que ultrapassa), reúne 308 espécies, fechando com índice de autores e tradutores, e um índice geral.

O título número 1 é Henrique de Campos Ferreira Lima, "Bibliografia Portoghese del Risorgimento", na Rassegna Storica del Risorgimento, 27, fasc. 5.', 1940 [Roma], pp. 451-462. Dito assim, o leitor não se apercebe da riqueza aí contida (doravante, em www.risorgimento.it/rassegna/index, Agosto 2011). A convite do então director do Instituto Italiano em Portugal, Aldo Bizzarri, Ferreira Lima dividiu o trabalho em quatro partes: escritores do Risorgimento Leopardi, Manzoni, Silvio Pellico, Carrer, e respectivas traduções ou estudos críticos lusitanos; originais portugueses referidos ao Risorgimento; obras estrangeiras vertidas em português; vária, com informes sobre a presença albertina no Porto. Interessa-nos a segunda secção, onde também são abordados Garibaldi, Victor Manuel, Cavour, Cialdini, os irmãos Durando, Cucchiari, Ramorino, etc. Adiante-se, já, citação-resumo:

${ }^{1}$ Lisboa, , 2, n. ${ }^{\circ}$, Janeiro-Março de 1961 [Fundação Calouste Gulbenkian], pp. 67-141. 
Carlos Alberto, depois da sua abdicação em seguida á batalha de Novara, veio acolher-se á hospitaleira terra portuguesa. Passou em Valença do Minho, onde, na casa em que pernoitou de 16 para 17 de Abril, foi colocada lápide comemorativa em 1883, e estabeleceu residência na cidade do Porto. Nos jardins do Palácio de Cristal desta cidade, por iniciativa de sua irmã, a princesa Augusta de Montléar, foi erguida [primeira pedra em 1850], em sua memória, uma magnífica capela da invocação de S. Carlos Borromeu.

Muitos poetas portugueses fizeram vibrar a sua lira em homenagem ao ex-rei da Sardenha, que conseguiu atrair as simpatias dos portugueses, em especial dos portuenses, um dos quais mandou cunhar, em 1854, uma medalha dedicada á sua memória. (pp. 451-452)

Manuppella, entretanto, considera os seguintes pontos: I. "Riflessi portoghesi di alcuni scrittori italiani", incluindo no cinema, com bibliografia activa e passiva em tradução (Petrarca, Machiavelli, Leonor / Eleonora da Fonseca Pimentel, Vittorio Alfieri, Ugo Foscolo, Manzoni, Silvio Pellico, Cesare Cantù, Antonio Bresciani); II. "Esuli politici italiani in Portogallo"; ideias, homens e acontecimentos; III. "Pro e contro l'unità d'Italia", em que entra o poder temporal do papado, ou "questão romana", não reduzida a Antero de Quental'; IV. "La Casa Savoia”: Carlo Alberto (espécies entre 149-198, pp. 102-111), Vittorio Emanuele II, Maria Pia, Umberto I, Amedeo Fernando Maria di Savoia, Duca d'Aosta; Cavour e Garibaldi, ou V. "La mente e il braccio"; enfim, sexta secção sobre os pontífices Pio IX e Leão XIII.

Entre Ferreira Lima e Manuppella, houve tese de licenciatura de Maria Luísa Gomes Brandão, A Itália na Literatura Portuguesa no Século XIX. Contribuição para o Estudo das

2 Se, temporalmente, não se podia incluir Luciana Stegagno Picchio, "Italie mythique d'Antero de Quental. De Garibaldi à St. François d'Assise”, Antero de Quental et l'Europe. Actes du Colloque, Paris, FCG/CCP, 1991, pp. 147-158, não ficava mal lembrar José Bruno Carreiro, Antero de Quental. Subsídios para a Sua Biografia [1948], vol. I, 2. ${ }^{\text {e }}$., Instituto Cultural de Ponta Delgada, 1981, pp. 179-182. 
Relaçôes Culturais Luso-Italianas (Faculdade de Letras de Lisboa, 1946), modesta ilustração daquele, que não conhece, mas peça bibliográfica por este ignorada. Convém, entretanto, juntar novas pepitas, num discurso coerente ao redor dos dois últimos anos de Carlos Alberto.

Desde 1848, a Itália é, entre nós, um pouco mais do que ópera. A primeira Imprensa socialista toma-a como exemplo próximo de outras revoltas nacionalistas:

A aniquilação de poder austriaco na Italia, assim como a quéda de varios tyrannetes como os duques reinantes de Modena, Parma etc. fazem esperar que em breve a graude [grande] nação italiana reunida n'um pensamento unico, dirigida pelas mesmas idéas e ligada por interesses identicos adquira a final [afinal] a posição, que lhe compete na Europa. (O Seculo, Lisboa, n. ${ }^{\circ}$ 1, 10-4-1848, p. 14)

"Italia que livre fora / Seu pendão livre erguerá." (p. 16), espera o anónimo redactor. Iniciava-se um forte movimento de solidariedade literária, em que os designados ultra-românticos irmanavam povos, da França à Hungria e Polónia:

Porque os verdadeiros mandatarios do povo não são os que governam. Tudo isto que ainda hontem se soffria, hoje revolta - revolta por que o povo quer, deseja conhecer a verdade!....

Se a Italia se transportou d'alegria em honra de Carlos Alberto, é porque viu no Piemonte uma força organisada com as antigas côres italianas, é porque a Italia quer pertencer a si, e deixar de ser austriaca. Mas a Italia, hade repulsar as concessões mesquinhas do poder, que mandou bombardear Palermo; e a Italia hade dever á sna [sua] união e coragem a honra, que não morre, de reconquistar seus direitos.

Se Roma s'enthusiasma agradecida, pelos primeiros e sublimes actos de Pio 9. ${ }^{\circ}$, é porque vê nascer do alto do Vaticano a aurora da emancipação. (O Seculo, n. ${ }^{\circ}$ 2, 16-4-1848, p. 23) 
Neste quadro, "A heroica cidade de Milão hastea desassombrada o pendão da liberdade. Venesa proclamou a republica, e revindicou a sua nacionalidade." (p. 32)

O anónimo é, afinal, António Pedro Lopes de Mendonça (duas pobres citações em Manuppella, ausente em Ferreira Lima), ao tempo, já não só folhetinista, mas crítico entusiasta dessa geração que, em verso, tanto incentiva à luta como agoniza entre ciprestes:

Em seguida á França a Italia prosegue na grande obra das suas liberdades, e apesar dos obstaculos, que de toda a parte se lhe offerecem, ella hade sahir vencedora.

Hade desenganar seus antigos dominadores, e victoriosa nas batalhas campaes, como o foi dentro dos muros de Milão, hade conseguir sua independencia e sua nacionalidade; reduzindo por esse modo ao pó esses tratados infames, que desde 1815 faziam a vergonha da Europa e o oprobrio da humanidade. (O Seculo, n. ${ }^{0} 7,22-5-1848$, p. 109)

As revoluçôes de 1848 elevam o pensamento, o "vigor poético" de um Francisco Gomes de Amorim, cujos poemas Garibaldi e A queda da Hungria (depois, em Cantos Matutinos, 1859) merecem chamada em Ensaios de critica e litteratura (1849), refundido em Memorias de litteratura contemporanea (1855, p. 307). Mendonça encerra o n. 9 d'O Seculo (7-6-1848, pp. 143-144) com Nápoles, também inspirando versos de Luís Augusto Palmeirim, Mazaniello ${ }^{3}$ :

O HEROICO exemplo dos povos perdoando com generosidade aos seus oppressores foi completamente perdido.

Os tyrannos cedem para se revoltarem, e se, como os tigres, conseguem saltar de improviso sobre sua victima, ei-los cevando-se de sangue, e folgando de morder as suas entranhas ainda palpitantes.

\footnotetext{
${ }^{3}$ Poesias, 4. ${ }^{\mathrm{a}}$ ed., Lisboa, 1864, pp. 98-101.
} 
Não ha um só povo que não tenha sido generoso, levantando o grito da liberdade.

Os Napolitanos [,] imitando os outros povos, perdoaram todas as offensas que tinham recebido de seus reis, e entre os vivas entoados no enthusiasmo da revolução, nunca esqueceram de saudar a realeza.

O rei Napoles cedeu a tudo, prometeu tudo, em quanto [enquanto] não podia esmagar traiçoeiramente o poder do povo; e este, confiado nas promessas enganosas do monarcha, esperava tranquillo gosar da liberdade que havia conseguido; mas de repente se vê assaltado por hordas de assassinos, que á voz do monarcha tudo assollam, tudo destroem!!

A cidade de Napoles hoje reduzida a um vasto cemiterio dá uma tremenda lição aos povos, ensinando-lhes que antes de tudo é necessario fazer justiça.

Se os Napolitanos se tivessem lembrado do passado, não acreditariam nas palavras de um tyranno; e na sua magnanima generosidade não esqueceriam as leis da justiça.

O imperador d'Austria tambem se prepara para seguir o exemplo do rei de Napoles, e se Vienna não estiver á lerta [alerta] teremos a repetição dos horrores, de que foram victimas os Napolitanos.

A reacção dos despotas prepara-se com arrogancia, é preciso que os povos redobrem de energia; senão, os esforços feitos em prol da liberdade serão ainda uma vez baldados.

Estamos neste pé, quando Custoza cai sob Radetzky (25-7-1848): ignora-se que o "Quinzenario Litterario, Scientifico e Recreativo" Aurora (Porto, 1867-1868) deu, do redactor Alfredo de Sousa Pinto, o 'romance original' A Noiva de Custozza, cuja acção se passa numa Veneza de amores e revolta de jovem húngaro anti-habsbúrgico; pior é quando "o martyr de Novara" ${ }^{4}$ (23-3-1848) - curiosa santificação de rei peregrino até aos loca sancta lusitanos - verga sob as condições

\footnotetext{
“ Tomás Ribeiro, "Bem-vinda" [já em Coroa Poética [...], 1862], Sons que passam,

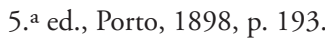


do armistício e abdica em Vítor Manuel II: "Quando viu que tudo estava perdido, pelas 6 horas da tarde, êle, que se havia exposto, desde as 11 horas da manhã, como um simples soldado, à saraivada dos projécteis inimigos, procurou a morte com um verdadeiro delírio. Foi preciso que o General

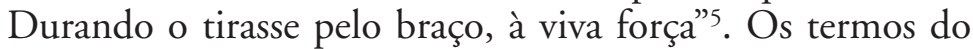
armistício são transcritos no mesmo Arquivo Nacional, n. ${ }^{\circ}$ 71, 19-5-1933, pp. 302-303. Reinara 18 anos, e parte, de imediato, com um só criado, ou dois, conforme as vozes: vai para onde?

Mau grado as insígnias reais, a carruagem atravessa as linhas austríacas. E apesar da sua figura, disfarçado sob o título de Conde de Barge, ninguém o reconhece.

Seguimos, agora, o périplo da correspondência de João António Lobo de Moura, encarregado de Negócios de Portugal em Turim, ao ministro Visconde de Castro. Com Ferreira Lima e Manuppella, é fundamental a recolha de Eduardo Brazão, "A unificação de Itália vista pelos diplomatas portugueses. 1848-1870", nos volumes 37, 1961 [1848-1860, pp. 1-398] e 38, 1962 [1861-1870, pp. 1-534] da revista Biblos (Coimbra; em livro, I, 1963; II, 1966).

Muito noticioso desde 11-1-1848, Lobo de Moura mostra bem como a diplomacia europeia inventa passos ao ex-monarca, sobre o qual conclui: "Destituído de toda a espécie de talentos militares hoje só o recomenda o seu infortúnio!" (37, p. 145)

É um balanço morno, longe da violência de outros, como veremos. No meio termo, está um vencido que vai conquistar os tripeiros. Ao infortúnio somam-se 27 dias de jornada, até à Hospedaria do Peixe - no palacete do visconde da Trindade, que fora do $2 .^{\circ}$ visconde de Balsemão, reproduzido no Archivo Pittoresco, 4, 1861, p. 401 -, na Feira das Caixas ou Praça dos Ferradores, já Praça de Carlos Alberto em 1876,

${ }^{5}$ Arquivo Nacional, n. ${ }^{72}$, 126-5-1933 [Lisboa], p. 310. 
onde o lazer encontrará "doçuras da luz na iluminação veneziana"6.

O Periódico dos Pobres no Porto (17-4-1849) di-lo chegado a Vigo, a 13. Falta romancear esta deriva de príncipe, desembocando no noroeste português com dois criados, um dono de hospedaria em Vigo e quatro cavalos com bagagem, a caminho do Porto - antes, ainda dorme em Viana do Castelo e Póvoa de Varzim -, onde entra em 20 de Abril. No Carvalhido - reza a edição de 21 -, às 10,30 h, é recebido pelas máximas autoridades da cidade, que o saúdam em francês. Recusa hospedagem no paço episcopal; recusa coche do Estado e dois cavalos que o governador civil punha à sua disposição. Este informa que D. Maria II já lhe prepara o palácio de Belém, e mandará o vapor Mindelo buscá-lo, logo que ele telegrafe. Diz querer fixar-se no Porto "como um simples cidadão”, que irá agradecer a Sua Majestade, e dispensa a guarda de honra de infantaria.

Conhece o Porto pela resistência às invasões napoleónicas, mas não faz ideia do número de habitantes; agradou-lhe a bem tratada agricultura minhota, tal como o sossego das gentes.

Sampaio Bruno cita Maria da Felicidade do Couto Brown (Soror Dolores), "Na partida do cadaver de Sua Magestade Carlos Alberto" (O Nacional [Porto], 19-9-1849), e, acrescentando poetisa menor, ambas recenseadas em Manuppella (ignorando, com Ferreira Lima, Bruno), resume a atmosfera receptiva: "Naturalmente que o romanesco episódio final de Carlos Alberto, acolhendo-se ao Porto para aí expirar, inspiraria as musas melancólicas, como, com efeito, a de outra dama portuense inspirou, D. Maria Adelaide Fernandes Prata, a páginas 119 de seu volume de Poesias [1859]"”.

${ }^{6}$ Júlio Lourenço Pinto, O homem indispensável. Cenas da vida contemporânea, 1883, cit. em Trajectos. O Porto na memória naturalista, selecção e prefácio de Isabel Pires de Lima, Lisboa, Guimarães Editores, 1989, pp. 113-114

${ }^{7}$ Bruno, Portuenses ilustres [1907], Porto, Edições Caixotim, 2003, II, p. 91. 
Eduardo Brazão transcreve documento coetâneo que nolo retrata: "Era homem de estatura alta, magro e sisudo; vai à missa primeira que se diz no Convento do Carmo, está com toda a atenção, em pé, lendo em um pequeno livro durante a Missa, no meio do corpo da Igreja, como pessoa particular [,] e acabada a Missa saía entre o primeiro povo para sua casa, que era do Visconde de Balsemão.” (vol. 36, p. 98)

Neste meio tempo, os "obséquios feitos pela Nossa Rainha e seu Governo a El Rei Carlos Alberto" chegam a Turim, como informa Lobo Moura (22-5-1849): "Sei que El Rei Carlos escrevera à Rainha muito agradecido pelo mesmo motivo. É singular, segundo me disse pessoa que a leu, que nesta carta Ele não diz uma só palavra de seus filhos e netos." O retraimento psicológico e social é completo, mais perceptível na sequência:

O Intendente da Lista Civil me dirigiu um ofício pedindo-me de escrever ao Sr. Director das Alfândegas do Porto afim [sic] de que facilitassem todos os meios de desembarque e se visitassem só no aposento de El Rei 13 caixas, contendo prata, roupa de mesa e outros objectos do seu serviço que acompanha um empregado da Vedoria do Porto. [...] dizem que S. M. acha o clima do Porto inconstante, e não será de admirar, segundo alguns, que se passasse a Lisboa, ainda que outros supóem que se Ele deixar o Porto irá residir em cidade mais pequena e secundária. (Biblos, 37, p. 145)

Vai, de facto, em 3 de Maio, para a villa de Entre-Quintas (Manuppella reproduz litografia na p. 100), ou Quinta da Macieirinha, entre outras designações, que é, hoje, Museu Romântico. Acompanham-no inúmeros objectos ${ }^{8}$. Tem confessor e capelão no padre António Peixoto Salgado. Um dos

\footnotetext{
${ }^{8}$ Estão descritos em Manuel Engrácia Antunes, "Elementos para o estudo da estadia no Porto de Carlos Alberto, rei da Sardenha”, Ciências e Técnicas do Património, I série, vol. 2, Revista da Faculdade de Letras, Porto, 2003, pp. 545-573.
} 
seus médicos, Francisco de Assis Sousa Vaz, será Cavaleiro da Ordem de S. Maurício e S. Lázaro de Sardenha, com o título de médico honorário da casa d'el-rei da Sardenha, como lembra Bruno (II, p. 236). Ora, o Dr. Assis e colegas tratam moléstia do peito, quando o professor Riberi, que já acorre de Itália ao Porto, diz ser doença do fígado. Seguindo-se a estados de "marasmo", as "desastrosas notícias da saúde de El Rei Carlos Alberto" - afinal, resumida a tísica - correm a Europa e já em 26 de Junho chegam a Lobo Moura, em tratamentos na Suíça (Biblos, 37, p. 154). Jornais apressados dão-no morto antes de tempo. A 26 de Julho, recebe o sagrado Viático e a Bênção Apostólica. Morre em 28 de Julho.

As autoridades que o haviam recebido chegam tarde ao apelo do cônsul-geral da Sardenha, De Launey, seu mais constante companheiro. O Estandarte (Lisboa, 31-7-1849) traz nota do telégrafo central do Porto, dirigido ao presidente do Conselho de Ministros e ao ministro dos Negócios Estrangeiros: "Sua magestade Carlos Alberto faleceu hoje ás 3 h. e $30 \mathrm{~m}$. da tarde. Em 28 do corrente." Salvas de tiros, toques a finados, sinais de luto nas embarcaçóes surtas no rio, encerramento do Teatro Lírico - tudo responde ao passamento de um príncipe melancólico. $\mathrm{O}$ generoso acolhimento - agora, recolhimento - da cidade terá um voto de gratidão na Câmara dos Deputados Sarda, em Outubro, quando se fizer o funeral. Em 8 de Agosto, chegara a notícia da morte a Turim; a 17, partia de Génova o príncipe Eugénio de Sabóia Carignano para transladar os restos mortais e distribuir cruzes e ordens aos empregados portugueses que o assistiram.

Antes e depois da morte, corria, pois, muita lírica simpática ao ilustre visitante: n'O Nacional e n'O Jornal do Povo, portuenses - Camilo Castelo Branco, entre outros -, n'A Revolução de Setembro, Revista Popular e Archivo Pittoresco, lisboetas, entre alguns mais referidos em Manuppella, que falha muitos (Revista Universal Lisbonense, 1849; O Occidente, vol. 22, n. ${ }^{\circ}$ 741, Julho de 1899, p. 166, etc.), bem 
como desconhece reproduções do soberano no apartado de Iconografia da Biblioteca Nacional de Portugal.

A política, todavia, olhava para o misterioso trânsfuga de maneira oblíqua, e bem pode ter sido carta "reservada" de Lobo de Moura (3-6-1849) a refrear eventual aproximação de Lisboa ao príncipe caído, em inesperado fotograma:

El Rei Carlos Alberto queria a guerra, ou fosse ambição, ou fosse o amor próprio e desejo de sacrificar à apetecida reputação do homem consistente e tenaz de propósito, ou, como alguns pretendem, até visões misteriosas que iluminavam o espírito do infeliz Monarca, ou, como outros supõem, susceptibilidades pundonorosas que o impeliam a responder às caluniosas vozes que o acusavam de traição com a devoção e sacrifício da Sua Pessoa à Causa da Independência Nacional. Era pois El Rei Carlos Alberto o mais decidido instigador da guerra, e infelizmente no seu pensamento político não tinha outros aliados senão no interior o Partido Revolucionário, no exterior os fautores da Propaganda Republicana. Ele era por carácter, educação e princípios Realista exaltado, achava-se agora ligado com os inimigos mais encarniçados da Monarquia. (Biblos, 37, p. 147)

...Mas também não agrada a troianos. Ao elogiar Mazzini no seu Almananak Democrático para 1852 (Lisboa, 1851), Henriques Nogueira a acusa o rei de "intençôes ambiciosas", de, em vez de fazer da guerra contra a Áustria uma causa nacional, só olhar ao engrandecimento da Casa de Sabóia: "A campanha de Carlos Alberto empreendida com a ideia egoísta de aumentar o território piemontês com a junção da Lombardia, e com o fim reservado de evitar ali a proclamação da república, amorteceu a energia popular, [...]"9.

Assim, desapreciado por uns e outros, nas altas esferas da diplomacia e do republicanismo nacionais, mas carinhosa-

9 José Félix Henriques Nogueira, "J. Mazzini”, Obra Completa, tomo I, Lisboa, INCM, 1976, p. 189. 
mente recebido na Cidade Invicta; com "visões misteriosas" e a melancolia vertida em teimosia de guerreiro; com repentes e excessivo - assim se finou um raro soldado, talvez príncipe romântico, a exigir novas aproximações. 